\title{
Communication as a Strategy for Implementing the Language- in-Education Policy in Botswana Primary Schools
}

\author{
Eureka Mokibelo \\ University of Botswana
}

\begin{abstract}
This paper examines the role that communication plays as a strategy for implementing the language-in-education policy (LiEP) by teachers, school management and education officers in Botswana primary schools. Communication is at the pinnacle of the implementation of the language-in-education policy. This is confirmed by the diffusion of innovation and the eagle leadership theories. If ignored, it could lead to frustration and despair amongst policy agents. This study adopted the qualitative approach with open ended questionnaires, interviews and classroom observations techniques to investigate the problem. The findings indicate that effective communication was lacking in the implementation process of the language-in-education policy and this has led to disconnectedness, detachment, burn out and frustration amongst teachers. In the light of these findings, this study suggested the development of leadership and management in education officers, school management and teachers to raise their awareness about the critical role they can play in successfully implementing the LiEP through diverse communication channels. This study concluded that there should be, a reflection and change of behaviour by both senior personnel and teachers in primary schools to achieve the objectives of the language-in-education policy.
\end{abstract}

Keywords: communication, language-in-education policy, implementation, education officers, school management, teachers

\section{INTRODUCTION}

The use of languages of instruction in primary schools requires school leadership, educational authorities and teachers to constantly communicate through diverse channels. The languages of instruction present challenges, risks and they require constant collaboration and communication processes that are effective. Previous studies point to the importance of communication in primary and secondary schools regarding the policy or curriculum implementation (see Arlestig, 2007; Pansiri, 2008, Virgilio \&Virgilio, 2001). For example, Arlestig (2007) reports that in one Swedish school, communication was not used as a tool for stimulating learning and encouraging dialogue about important pedagogical and school improvement issues and this impacted negatively on school performance. Virgilio and Virgilio (2001) note that principals are important people to constantly communicate about the curriculum of the school to bring about expected changes. These scholars indicate the importance of communication by leadership in various countries of the world.

Communication involves sharing ideas, knowledge, perspectives and experiences (Stubbs, Moss \& Papastefanou, 2012). Lotitch (2013) believes that communication is a two way process that allows exchange of ideas between policy makers and policy implementers and it helps keep educational processes to run smoothly. This definition suggests that communication as an implementation strategy is critical and has to be clearly articulated before the LiEP can be rolled out. Again, it suggests that people should work together and that every policy agent must not be undermined or underestimated in terms of communication. Also, it means that senior 
personnel have to solicit their subordinates' ideas through various communication processes to enable them (senior personnel) to address issues affecting the implementation processes.

The significance of communication is highlighted in this paper because it can lead to success or failure of the implementation of the language-in-education policy in primary schools. With the academic results held high by the public, communities, Ministry of Education and Skills Development and parents, it is important to improve communication in Botswana primary schools. This will help create a culture where teachers, school management and education officers have an opportunity to be heard on what is happening in classrooms by higher educational authorities and other stakeholders. Evidence from the study indicates that lack of communication can brew frustration, devastation, low morale, poor academic results, lack of parental involvement and negative attitude amongst teachers to name a few in the school environment. Therefore, it is crucial for primary schools to think of communication as a means through which teaching and learning environment, and students' performance can be improved. In the light of this, this paper problematizes the issue of communication in primary schools. It therefore calls on school leadership, both internal and external, to take a closer look at how the problem of communication retards successful implementation of the language-ineducation policy in schools.

\section{Communication for implementing the language-in-education policy}

Communication is regarded as a concrete strategy that keeps implementers abreast with the implementation processes (Contandriopoulos \& Brouselle, 2012). In education, the objective of communication should be clear to education officers, school management and teachers to enhance successful implementation of the LiEP. This suggests that communication is a central component of any change or process. Thus, the greater the impact or change, the greater the need for clear communication (Contandriopoulos \& Brouselle, 2012). Communication should be from top to bottom and from bottom up. The reason for bottom up communication is that teachers and school management should report to education officers on whether or not: learners are responsive to the policy; there are problems of comprehension, and there is a need for intensive approaches for them to acquire basic language skills in target languages.

Communication demands that there be an audience. As Savio and Nikolopoulos (2010) argue, the audience may come from different backgrounds, and may have different interests. This would influence the way a policy is implemented and how the audience would receive the information. In this case, teachers are the audience and are also agents of the policy. This means that the background of the audience could determine the implementation strategies, and these strategies should be of different shapes and specifications (Savio \& Nikolopoulos, 2010).

Training should be done at different levels such that each implementer can understand their roles. For example, teachers should understand how they should implement the policy even in complex situations by applying strategies suitable to learners in different learning environments. Equally, education officers and school management should also understand their role as external and internal supervisors by monitoring the implementation process. This would help them identify gaps and challenges faced by teachers in the classrooms. In this regard, education officers should link primary schools and the Ministry of Education and Skills Development (MOESD) through brief workshops and seminars. Education officers should understand what they should be monitoring and supervising in regional education offices. They should keep a clear record and liaise with primary schools and MOESD. Therefore, rigorous training for education officers, school management and teachers as agents of the 
policy is necessary to avoid a fluid situation where there would be no accountability and confusion of roles.

Closely linked to communication is the issue of collaboration. Collaboration is defined as any joint activity that requires interaction from two or more groups of people by working together (Bardach, 1998). This interactive process involves actors who share roles, norms, or organizational structures and are able to make collective decisions (Gray \& Wood, 1999). In education, the expectation is that teachers, school management and education officers should collaborate on the implementation processes. The group is expected to address complex and specific problems from the schools and regions and make collective decisions on them. Implementers should collaborate and that would indicate their commitment to the implementation process (Bachelor, 1985). It has been argued that even with the most logical policy imaginable, if those responsible for implementing the policy are unwilling or unable to collaborate, very little will be achieved (Bachelor, 1985). The expectation in this study was that education officers should show commitment through networking; dialoguing and interacting with primary schools in their regions and address whatever problems that would emerge from the implementation processes. The process should replicate a chain in which education officers should liaise with school management and teachers on issues of benefits, weaknesses and challenges of the LiEP. All practices, experiences and ideas from schools and classrooms could be shared at regional level through the efforts of the education officers.

Communication needs to be made as practical as possible with strong executive-level support for the delivery process by school management and education officers. If implementers at supervisory level are committed to supporting their subordinates through engaging and using models of best practices, the implementation processes could bring about significant changes and successful implementation in regions, schools and classrooms. An over simplification or overlook of communication could result in unsuccessful LiEP implementation. Communication as an implementation strategy indicates that LiEP implementation has to be well thought out because discrepancies often exist between what is intended and what is enacted. Further, policy implementers often experience contextual constraints especially at local level and thus get stuck in real operations. The view that policy objectives and communication should match poses challenges for policy makers and policy implementers. Policy makers may produce good policies, but unforeseen circumstances and unpredicted outcomes such as ineffective communication may result in different translations of the policy by implementers. Furthermore, the implementation may be compounded by resistance by implementers, who may view the policy negatively or simply differently than was intended by policy makers if communication is lacking (Wang, 2006).

\section{CONCEPTUAL FRAMEWORK}

This paper used two theories to identify studied primary school practices on communication. The two theories: the diffusion of innovation and the eagle leadership philosophy were chosen to give a clear picture of what policy implementers could be doing to effectively communicate and implement the language-in-education policy. Again, the two theories assist in clearly identifying roles of who should be doing what in the implementation processes.

\section{The Eagle Leadership Philosophy}

The first theory is that of the eagle leadership philosophy by Stephen Covey (2004). The theory is used as a backbone to explain the roles and practices of implementers at different levels for successful implementation of the language-in-education policy. The characteristics of an eagle are used to explain what the leadership in the Ministry of Education and Skills Development 
could be doing for successful implementation of the LiEP in regards to communication. Stephen Covey (2004) discusses principles of leadership that reflect the scouts of an eagle that can help to build, energize and inspire senior personnel as internal and external supervisors in their endeavour to implement the language-in-education policy in primary schools. The principles are important for management and supervision because they can assist in using cutting edge methods and ultimately positively impact on delivery techniques. Most importantly, the principles could impact on communication which can effectively enhance the implementation of the LiEP. This may result in bringing about greater fulfillment and success in the implementation of the language-in-education policy. Only five of the characteristics of an eagle were used in this paper. Those eagle leadership philosophy principles are as follows:

Eagles have a vision. They watch things closely and very attentively. Also, they watch what is happening below, around and above them. Even when flying high, eagles watch keenly on their prey. Covey (2004) sees vision as a successful leadership characteristic. A leader who has a vision would guide, lead and focus the team towards the achievement of their goals through effective communication. Education Officers and School Management should have visions to guide teachers in the language in education policy implementation processes. They should make the implementation processes possible. They should also be confident that they can open doors for changes required by the implementation process through communication. While a policy is rolled out from the top, as it is the case with the current one, it is the responsibility of the education officers and school management to identify ways in which messages could be effectively communicated. For example, in a school setup, communication that could assist in effective implementation of the policy could be through mini workshops, written communication and oral presentations. Like Schalkwyk (1992) observes, they should make communication a tool for survival as risks and challenges emerge in the implementation processes.

Covey (2004) states that eagles fly to greater heights than other birds. An eagle does not mingle around with pigeons. Pigeons scavenge on the ground, grumble and complain all day long while eagles fly high and make less noise waiting for opportunities to glide with the current of the storm. Flying high can make education officers and school management to solve problems and challenges relating to the implementation process through proper communication channels. While teachers complain about problems they encounter in the implementation process such as communication barrier, high school dropout, differences in cultures and learners being unresponsive to the policy, management could be flying high as supervisors to observe, imagine, reflect and see what is happening below - in the teachers' classrooms. They have to identify possible communication challenges to address what they have observed. This will open channels for communication with teachers for their development and growth in the implementation of the LiEP.

Eagles are fearless; they face problems, risks and challenges their attackers head on. They never surrender to the size or strength of their prey. Instead, they give a fight to win their prey and regain their territory. Covey (2004) argues that management is full of challenges; it needs people who can strategize, protect their territory and positions as great supervisors. Again, management needs people who can make decisions on emerging problems and make quick, short and long term fixes. This could help education officers and school management to hold on strongly to their weapons which in this case are their various communication strategies to face challenges and risks that emerge on the implementation process fearlessly. There is no single and simple answer, but a systematic and coherent approach to effective communication needs to be done with strong attributes by the senior personnel. 
Eagles are tenacious; they keep a firm hold of their principles and are persistent in what they do. When other birds fly away from the storm, an eagle would spread its wings and use the current to soar to greater heights; it takes advantage of the storm. Implementing a policy has many challenges and risks that need both short and long term solutions. Despite this, education officers and school management can rise to greater heights if they communicatively take up challenges head on. (Covey, 2004). This depends on the skills, experiences and time that should be availed by the senior personnel to debate and make decisions on emerging issues from the implementation process.

Eagles nurture their younger ones; the bird has the ability to nurture their young ones in a gentle, attentive and empowering manner. When the mother eagle sees that time has come for it to teach the eaglets to fly, she gathers an eaglet onto her back, and spreading her wings, flies high, she would swoop out from under the eaglet and allow it to fall. As it falls, it gradually learns what its wings are for until the mother catches it once again. The process is repeated until the eaglet has mastered how to fly and has become independent. Similarly, education officers and school management have to nurture teachers at various levels of the Language in education policy implementation process. They have to communicate the delivery services to teachers. They have to guide, give them challenges, direct and empower teachers until they are grounded in the implementation process. Servaes (2008) argues that interpersonal communication requires leadership that is sensitive to the needs and views of others, have good listening skills and attitudes favourable to working with people as a trusted helper rather than an agent of authority telling people what to do.

In essence, the eagle leadership skills also require effective communication to overcome barriers and incomprehension, illustrate new ideas and techniques, facilitate cheaper and easier production and good management skills and transformative teaching and learning skills.

\section{The Diffusion of Innovation Theory}

The second theory is that of the Diffusion of Innovation Theory conceived by Everette Rogers (1995). The theory is central to the process of communication within an institution or organization. According to Rogers (1995), diffusion is the process by which an innovation is communicated through certain channels over time among members of a social system. It is a special type of communication concerned with the spread of messages that are perceived as new ideas. Rogers (1995) defines innovation as an idea, practice or object perceived as new by the individual. For this paper the new idea perceived by policy implementers is the implementation of the language-in-education policy which has to be diffused to the school management and teachers to achieve educational goals. How it is communicated by the senior personnel to the subordinates is vital to this paper.

According to Rogers (1995) diffusion has four elements that characterize it: innovation, communication channels, time and the social system which shall be discussed individually. Rogers (1995) maintains that innovation or an idea can spread quickly or slowly depending on certain characteristics. These characteristics may determine an innovation's rate of adoption: The characteristics are relative advantage, compatibility, complexity, trialability and observability. Rogers (1995) claims that relative advantage is the degree to which an innovation is perceived as better than the idea it supersedes, it does not matter so much if an innovation has a great deal of objective advantage, what matters is whether or not an individual perceives the innovation as advantageous. Rogers (1995) also argues that compatibility is the degree to which an innovation is perceived as being consistent with the existing values, past experiences and needs of potential adopters. An idea that is incompatible 
with the values and norms of a social system will not be adopted as rapidly as an innovation that is compatible. Rogers (1995) defines complexity as the degree to which an innovation is perceived as difficult to understand and use. Some innovations are readily understood by most members of a social system while others are more complicated and will be adopted more slowly. Rogers (1995) suggests that innovation is based on trialability which is the degree to which an innovation may be experimented on a limited basis. According to Rogers, new ideas that can be tried on the installment plan will generally be adopted more quickly than innovations that are not divisible. Rogers (1995) also claims observability in innovation which he defines as the degree to which the results of an innovation are visible to others. The easier it is for individuals to see the results of an innovation, the more likely they are to adopt it. According to Rogers, such visibility is believed to stimulate peer discussion of a new idea.

Relating the above to this paper, policy implementers have to see the language-in-education policy as a policy that will advantage all students, they have to see to it that this policy is consistent with the realities of classroom experiences and it solves some of the problems that are policy related. Hence, for the policy agents, there must be that sense of belongingness and ownership of the policy for them to spread its message. If the policy is not compatible with practices and experiences of the target people and also presents some complexities, it might be difficult for policy implementers to implement it. Important is the trialability part, if the policy limits the implementers' potential, they might end up interpreting it the way it suits their student population or they may end up not adhering to it. The results of the implementation processes are important as feedback and therefore must be visible such that whatever risks and challenges emerged from the implementation process could be addressed. The results also could stimulate collaboration and networking between external and internal implementers in regions to address emerging issues from the implementation process.

Rogers (1995) highlights the concept of time dimension in diffusion in three ways. First, there is the innovation-decision process, which is the mental process through which an individual passes from knowledge of an innovation to forming an attitude towards it, to a decision to adopt or reject it, to implementation of the new idea and to confirmation of this decision. An individual seeks information at various stages in the innovation-decision process in order to decrease uncertainty about an innovation's expected consequences. The innovation-decision also goes through five steps: the person becomes aware of an innovation and has some idea of how it functions; a person forms a favourable or unfavourable attitude towards the innovation; a person engages in activities that would lead to a choice to adopt or reject the innovation; a person puts an innovation into use; and lastly a person evaluates the results of an innovationdecision already made. Second, is the innovativeness of an individual or other unit of adoption. Innovativeness in this case is the degree to which an individual or other unit of adoption is relatively earlier in adopting new ideas than other members of a social system. The innovativeness also has five categories: innovators - $2.5 \%$; early adopters - $13.5 \%$; early majority $-34 \%$; late majority $-34 \%$; and laggards $-16 \%$. Third is the rate of adoption. The rate of adoption is the relative speed with which an innovation is adopted by members of a social system. This is also influenced by the five perceived attributes of an innovation.

Relating to the above, in the process of implementation, implementers have to be aware of the implementation process and how it functions. Once this awareness has been raised either through training or other means, implementers could develop a favourable or unfavourable attitude towards the policy. The next step would be to put the idea to practice and see if it could be adhered to or not and that is when it can be adopted on a positive or negative note. The degree of adoption will vary depending on awareness, compatibility, complexity and 
practicability. The majority of implementers could be clustered around the favourable or unfavourable depending on the practicability of the policy in their schools or area.

Rogers (1995) specifies the social system as the last characteristic in diffusion. The social system is defined as a set of interrelated units that are engaged in joint problem-solving to accomplish a common goal. First members of the social system may be individuals, informal groups, organizations or subsystem. The second area of research involved how norms affect diffusion. Norms are the behavior patterns of members of a social system. The third area of research had to do with opinion leadership, the degree to which an individual is able to influence informally other individuals' attitude or overt behavior in a desired way with relative frequency. A change agent is an individual who attempts to influence clients' innovationdecisions in a direction that is deemed desirable by a change agency. In the process of diffusion of the policy, the leadership, both external and internal should play a leading role. The leadership should be influential and guide the direction of the implementation process through relevant and appropriate communication channels.

As noted above, the diffusion of innovation theory provides an insightful explanation of the conditions that indicate that an innovation will fail or succeed depending on communication processes involved. First, the theory claims that diffusion of innovation involves diversity of people and therefore needs systematic delivery of messages that are well planned. Secondly, the theory suggests training on delivery services to sensitize change agents of the achievement of common goals because it demands knowledge and awareness of an innovation and how it may function. Third, the theory demands clear identification of roles in language-in-education policy implementation. This means that Education Officers (EO) should clearly understand their role in diffusion of innovation on the implementation process down to the School Management (SM). The SM too has to understand how and what they need to do to disseminate information to teachers. The leadership role at the two different levels has to stand out. Again the theory challenges the EOs, SM and teachers to have a strong relationship. The two leadership roles and teachers need to collaborate and network to close the gaps, attend to risks, challenges, failures and celebrate successes together. The theory also challenges the leadership to be empowered such that they can adopt effective measures for information dissemination to achieve intended goals. The theory encourages leadership to be well informed, responsive, interactive, motivated, trusted and make the implementation process a collective exercise. However, the theory depends too much on personal motivation and individual characteristics who are able to stretch themselves.

\section{RESEARCH METHODOLOGY}

This study adopted a qualitative approach to enable a thorough understanding of the implementation process from the participants' perspectives through getting first-hand information and observing how the implementation is done. The general aim of this study was to evaluate the implementation of the language-in-education policy in ethnically and linguistically complex classrooms in primary schools. The specific objectives of this study were to: investigate the views of the policy implementers about the implementation of the LiEP in ethnically and linguistically diverse regions, examine the implementation strategies in the implementation process, examine challenges encountered and establish solutions to those challenges. The study was conducted in six districts with primary schools that had ethnically and linguistically diverse learners. The districts involved were: North East, North West, Central, Kgalagadi, Kweneng and South East. The districts and primary schools were chosen strategically because in some areas children speak three to four languages and they may not be exposed to the languages of the school. 
Different levels of primary schools were targeted for different reasons. For example, Standard One was sampled because it is where the national language, Setswana, is used as a medium of instruction and English taught as a subject. Standard Two is where English as a medium of instruction is used after using Setswana for one year school calendar. In Standard Four, learners write their National Attainment tests in English and it was important to see how ready they were to use English as the language of the examinations. Also, Standard Seven was equally important because it is where learners write their primary school final examinations. Thus, it was vital to see the status in which they write their final examinations after being taught in English for six years.

Education Officers were issued with open ended questionnaires to write their views about the implementation process and were not interviewed due to their tight schedules. Their views were important because they supervised school leaders; they guided and monitored the implementation of the language-in-education policy through liaising with them and reporting back to senior personnel at the Ministry of Education and Skills Development.

The School Management teams were also issued with open ended questionnaires, but they were also interviewed to hear what they have to say about the implementation process in their respective schools and also to share their link with education officers. School leaders are the internal and immediate supervisors of teachers and have to report whatever problems, concerns and successes to education officers. They have to guide, supervise and monitor the implementation process at close range in the classrooms and the general school environment. In this regard, they provide first-hand information through their supervision and feedback from teachers.

Teachers too were issued with open ended questionnaires to write their views about the implementation process and were later observed in classrooms and were then interviewed. Teachers were important to this study because they implemented the policy in classrooms. They liaised with school management teams and were able to appreciate problems, risks, challenges and successes of the implementation process in their respective classrooms. Thus, it was necessary for them to provide first-hand information from schools and the guidance they get from the school management and education officers on the implementation process.

Data from questionnaires, interviews and classroom observations were compiled and analyzed according to the four key research questions to make sure they had been answered effectively. The answers were grouped according to the major and minor themes depending on the frequency of occurrence. It is from the answers from all policy agents that the issue of lack of communication emerged and hence problematized in this paper. 
THE RESULTS OF THE STUDY ON COMMUNICATION PROCESSES IN SCHOOLS

Figure 2: The results from the study

\begin{tabular}{|c|c|c|c|c|c|c|}
\hline \multirow[b]{2}{*}{ Region } & \multicolumn{2}{|l|}{ Education Officers } & \multicolumn{2}{|c|}{ School Management } & \multicolumn{2}{|l|}{ Teachers } \\
\hline & $\begin{array}{l}\text { Implementation } \\
\text { strategies }\end{array}$ & Challenges & $\begin{array}{l}\text { Implementatio } \\
\text { n Strategies }\end{array}$ & Challenges & $\begin{array}{l}\text { Implementation } \\
\text { strategies }\end{array}$ & Challenges \\
\hline $\begin{array}{l}\text { Ngamilan } \\
\text { d }\end{array}$ & & $\begin{array}{l}\text { Language } \\
\text { barrier, no } \\
\text { resources to } \\
\text { run } \\
\text { workshops } \\
\text { for teachers }\end{array}$ & $\begin{array}{l}\text { When we } \\
\text { inform the EO } \\
\text { about } \\
\text { language } \\
\text { problems, we } \\
\text { are told to } \\
\text { sort out the } \\
\text { problem } \\
\text { ourselves }\end{array}$ & $\begin{array}{l}\text { Language } \\
\text { barrier } \\
\text { Poor } \\
\text { academic } \\
\text { results } \\
\text { High school } \\
\text { dropout } \\
\text { No } \\
\text { workshops } \\
\text { for teachers }\end{array}$ & $\begin{array}{l}\text { Lecture method } \\
\text { Group work }\end{array}$ & $\begin{array}{l}\text { No support } \\
\text { from SM } \\
\text { and EO, no } \\
\text { workshops, } \\
\text { no brief } \\
\text { meetings, } \\
\text { no school } \\
\text { visits since } \\
5 \text { years }\end{array}$ \\
\hline $\begin{array}{l}\text { North } \\
\text { East }\end{array}$ & & $\begin{array}{l}\text { No time to } \\
\text { visit schools }\end{array}$ & $\begin{array}{l}\text { No workshops } \\
\text { for teachers } \\
\text { that address } \\
\text { the language } \\
\text { policy issues }\end{array}$ & $\begin{array}{l}\text { Language } \\
\text { barrier, } \\
\text { truancy, }\end{array}$ & $\begin{array}{l}\text { Lecture method, } \\
\text { group work }\end{array}$ & $\begin{array}{l}\text { No support } \\
\text { from SSM and } \\
\text { EO. No school } \\
\text { Visits }\end{array}$ \\
\hline Central & & $\begin{array}{l}\text { Spend most } \\
\text { of the time } \\
\text { in } \\
\text { administrativ } \\
\text { e } \\
\text { workshops }\end{array}$ & $\begin{array}{l}\text { No workshops } \\
\text { and seminars } \\
\text { for teachers }\end{array}$ & $\begin{array}{l}\text { Parents not } \\
\text { cooperative } \\
\text { and do not } \\
\text { attend } \\
\text { meetings }\end{array}$ & $\begin{array}{l}\text { Group work } \\
\text { Lecturer method }\end{array}$ & $\begin{array}{l}\text { No support } \\
\text { from SM and } \\
\text { EO. No school } \\
\text { Visits }\end{array}$ \\
\hline Kgalagadi & & $\begin{array}{l}\text { No resources } \\
\text { especially } \\
\text { transport, } \\
\text { areas of } \\
\text { supervision } \\
\text { far apart. } \\
\text { Difficult to } \\
\text { run a } \\
\text { workshop for } \\
\text { teachers } \\
\text { who are far } \\
\text { apart } \\
\text { because of } \\
\text { lack of } \\
\text { accommodati } \\
\text { on }\end{array}$ & $\begin{array}{l}\text { Only one } \\
\text { workshop last } \\
\text { year and it was } \\
\text { not on } \\
\text { language issues }\end{array}$ & $\begin{array}{l}\text { Language } \\
\text { barrier, high } \\
\text { school } \\
\text { dropout, } \\
\text { truancy }\end{array}$ & $\begin{array}{l}\text { Lecture method } \\
\text { Group work }\end{array}$ & $\begin{array}{l}\text { No support } \\
\text { from SM and } \\
\text { EO, no } \\
\text { workshops and } \\
\text { seminars }\end{array}$ \\
\hline Kweneng & & $\begin{array}{l}\text { There are } \\
\text { no } \\
\text { challenges, } \\
\text { teachers } \\
\text { have got } \\
\text { bachelor's } \\
\text { degree }\end{array}$ & $\begin{array}{l}\text { Workshops are } \\
\text { run for } \\
\text { Breakthrough to } \\
\text { Setswana } \\
\text { Programme for } \\
\text { Standard One } \\
\text { teachers only }\end{array}$ & $\begin{array}{l}\text { Language } \\
\text { barrier, high } \\
\text { school } \\
\text { dropout, } \\
\text { truancy }\end{array}$ & $\begin{array}{l}\text { Lecturer method } \\
\text { Group work }\end{array}$ & $\begin{array}{l}\text { Workshops are } \\
\text { for teachers of } \\
\text { Standard One } \\
\text { on Breakthrough. } \\
\text { No school visits } \\
\text { by EO }\end{array}$ \\
\hline Southern & & $\begin{array}{l}\text { The school } \\
\text { is doing } \\
\text { well }\end{array}$ & $\begin{array}{l}\text { Have workshops } \\
\text { with other } \\
\text { English medium } \\
\text { schools to } \\
\text { benchmark how } \\
\text { they } \\
\text { implement their } \\
\text { policy }\end{array}$ & $\begin{array}{l}\text { No } \\
\text { photocopiers } \\
\text { and } \\
\text { printers }\end{array}$ & $\begin{array}{l}\text { Lecture method } \\
\text { Group work }\end{array}$ & $\begin{array}{l}\text { No school visits } \\
\text { by EO }\end{array}$ \\
\hline
\end{tabular}

As shown in the table above, education officers seemed not to clearly understand their role as senior personnel in respect of the implementation of the policy. The column on implementation strategies is blank because they did not mention any implementation strategies in place as senior level to assist teachers with the implementation process. The 
expectation is that they would outline the communication strategies they used to communicate with school management and teachers to achieve the objectives of the language-in-education policy. A void column with no implementation strategies from EOs could only lead to a fluid system where it is not clear who is supposed to do what. It is clearly indicated from their answers that they spent time in workshops that focused on administrative issues.

The School Management teams in rural primary schools also did not bring any implementation strategies to their schools. They reported that the only workshops teachers had were for initiating learners into the Setswana programme and these workshops were not attended by all teachers. The SM was aware that there were poor academic results in their schools. They did not make any effort as management to address problems emerging from the implementation process. Again, they seemed not to understand that poor results could be emanating from their lack of communication and dialoguing with the teachers. SM mentioned a plethora of problems in their schools which could be indirectly caused by the lack of communication to improve the way they ran primary schools. However, there was an indication that they tried to communicate with their supervisors but were turned down. The expectation was to hear their loud voices regarding the efforts they made (implementation strategies they use) as SM to achieve the implementation process.

Teachers articulated clearly that there was no support in terms of communication provided by SM and EOs regarding the implementation of the policy. According to teachers, there were no workshops, meetings or brief discussion on delivery services, hence communication was lacking. It is evident from the data that teachers mistook implementation strategies to be pedagogical methods they used to teach learners which were seemingly common across the regions. It is only in one urban school that school management made an effort to dialogue and communicate with teachers and other teachers from English medium schools to bring about change in their schools and they seemed to be reaping the good results from such kind of communication because their results were always over 75 - 90\% pass.

In summary, the data provided by education officers, school management and teachers ran parallel with the communication processes within schools and regions. There was evidence of lack of communication from top to bottom. Teachers pointed a finger at School Management and Education Officers. All teachers denied seeing education officers in the schools for the last five years. They also lament the lack of support from school management.

\section{Education Officers' detachment from primary schools}

DISCUSSION OF THE FINDINGS

Communication is a key leadership skill that should be championed by Education Officers in the implementation of the language-in-education policy in primary schools. Education officers (EOs) are a link between primary schools and the Ministry of Education and Skills Development (MOESD). Thus, their influence and involvement through communication should be felt throughout the implementation process. The delivery of an efficient service responsive to the needs of primary schools on the LiEP implementation seem to be lacking from the EOs especially the communication strategy. Roger (1995) perceives leadership as critical to raising awareness and spreading new ideas and knowledge on how implementation functions can bring about desired change. Many problems such as poor results, high school dropout due to language barriers and lack of interest in schools linked to the LiEP implementation can be traced to whether information was communicated, how it was communicated and who communicated it. Rogers (1995) finds it imperative for EOs as supervisors to establish appropriate mechanisms that would accelerate the promotion of full implementation through 
various channels of communication. The EOs are the immediate service providers to school management (SM) and teachers with knowledge and information to assist in operationalizing the policy. Therefore, they need to extensively facilitate communication to clarify the guiding implementation decisions, what implementation strategies to use and to provide quick fixes while waiting for the long term ones.

Covey (2004)'s theory of eagle leadership philosophy suggests that EOs should have a vision to guide the SM. They should be able to know what is happening in schools and how that would impact on current and future administrative issues. The poor academic results in rural primary schools as this study reveals should have been an eye opener to EOs on how languages of instruction can impact negatively on the students' academic performances. In actual fact the EOs did not have much to say on how Setswana as a national language impacts on learners and on how transition to English is a difficult process for various reasons. Their voices were loud enough when it came to poor academic performance of students in Standard 4 and 7. This was probably because they have to be accountable for the academic results to higher educational authorities. They seemed not to be aware that the poor Standard 4 and 7 results could be partly due to ineffective communication strategies. Education officers' responses left doubts about their authenticity because they could be lacking empirical evidence from the schools they were supervising due to very minimal communication and limited school visits.

The eagle leadership philosophy emphasizes that it is the task of those charged with directing the implementation process to coordinate the activities of these implementers at lower level in a way that would lead to successful and effective programme performance. In this regard, the theory charges the EOs to note that LiEP implementation is highly interactive in nature and is characterized by negotiation and supporting teacher classroom practices. The diffusion of innovation theory (Rogers, 1995) also supports the interactiveness and the spreading of message by providing characteristics that demand leadership to effectively spread the message such as innovation, communication channels, time and special system. These form a process that demands all concerned in the implementation process to constantly liaise with one another to reach a common goal. This suggests that EOs could communicate through meetings to provide SM with up-to-date and relevant knowledge about educational trends and issues. Further, the theory cautions supervisors that LiEP implementation is complex and dynamic and is therefore influenced by sub-strategies of communication such as persuasion and encouragement. Therefore, it was important to get the input of the EOs in primary schools as they encouraged and persuaded the SM on how to implement the LiEP.

Arguably, the EO's communication strategies were limited and they ran parallel to what they could be doing to assist school management teams in the LiEP implementation. The Diffusion of Innovation Theory suggests that if implementers view the policy as complex, it might be difficult for them to understand and use it (Rogers, 1995). Hence, the purpose of communication strategies is to provide improvement and change that can facilitate and strengthen the process of learning through a second, third or fourth language, especially in regions where Setswana is not spoken as a first language and English is learnt as a third or fourth language. Such communication strategies should inform SM about specific factors that can be addressed through policy change and those that cannot. In the Australian Implementation of Programme and Policy Guide Initiatives report of 2006, the authors ask the questions that could also be relevant to Botswana situation. Those questions are:

a) Is the government sufficiently informed about the risks, challenges and practical aspects of the policy that may have an impact on implementation?

b) Have appropriate record keeping and accountability mechanisms been established? 
Concerning the above, the impression is that implementers at supervisory level are not well prepared and guided to handle new changes and are likely to fail in their efforts to effect change as data has already revealed in this study. The EOs' responses did not indicate forums where they met and discussed the above issues and questions. The EOs did not champion, were not persistent enough and did not have a firm hold on principles that were strong enough to sustain communication with regard to LiEP implementation.

The implementation of the LiEP required EOs to possess necessary communication techniques to impart to the school management and teachers. When one of the SM reported to her EO that the heterogeneity of classrooms makes it difficult to start learning in the national language because of the language barrier, an answer like, 'go and sort the problem out on your own' does not reflect possession of such a skill. The EO displayed a detached approach and this resulted in frustration in primary schools under their supervision. The quotation also indicates that EOs failed to face the storm like eagles, instead EO; "ran away from it like small birds". With all the responsibilities and demands of the LiEP implementation placed upon implementers, a clear vision would have been necessary.

\section{Disconnectedness between School Management and Teachers}

A policy is supposed to fulfill its intent through a delivery service plan that needs to be monitored and evaluated with effective communication. Findings indicated that while communication skills seemed necessary, no strong evidence had been found to suggest that there was any form of communication between SM and teachers in all rural primary schools studied. This led to disconnectedness. Communication between SM and teachers regarding implementation strategies which could promote the LiEP implementation was lacking. Virgilio and Virgilio (2001) highlight the role that school principals as instructional leaders play as a critical role in the LiEP implementation and must assume complete responsibility for change through effective communication. This change could be effected by providing communication techniques such as pre-service, meetings, workshops, small group meetings, bulletins, handouts and in-service meetings. These forms of communication are necessary to bring about desired changes. However, these were not observed in all the schools studied except in one urban school. These could add value to the LiEP implementation and increase confidence levels as well as personal development. Thus teachers were given a new curriculum at the beginning of the school year and were asked to implement it on a 'hit and run' in-service effort (see Virgilio \& Virgilio, 2001). The critical factor in this study was that the roles of the school management and teachers were left fluid and not clearly identified in the implementation process.

While SM's are increasingly decision makers and change agents, their role requires the use of effective communication to develop shared meaning, search and use information effectively. Effective communication can foster the acquisition of team working skills, enhance professional working relationships and reduce anxiety. Lack of effective communication skills from school management could lead to teachers resisting change and sticking to their routine and traditional ways of classroom practices as indicated by the findings of the study and this may not bring about expected changes. For example, in almost all the primary schools studied, teachers used the 'lecture method' indiscriminately to teach various subjects. The SM could be in the forefront of promoting development of positive attitudes, responsibilities and competencies in teachers required by the LiEP implementation.

While scholars observe that the principal should lead and unify his team at work for improved academic performance, this was lacking in rural primary schools. Pansiri (2008) also observed 
that in Botswana, teachers' perception of cooperation in primary schools shows that school management was not skillful enough to meet the needs of their staff. Teachers emphasized that collaborative power in instructional leadership was needed to balance power inequalities in school communities (Pansiri, 2008). However, no such meetings and discussions existed during the LiEP implementation. Hence, teachers interpreted and translated the policy in whatever way it suited them. Therefore, there was an indication that SM's were disconnected and not committed to the LiEP implementation. School management teams should involve speaking up, confrontation, complaining and reporting to higher education authorities. The SM required integration of skills and tasks embedded in communication for group development and teachers' growth (Virgilio \& Virgilio, 2001; Pansiri, 2008). It seems the innovation-decision process by (Rogers, 1995) runs parallel to schools' practices because it demands that the knowledge on the implementation process be passed on to the implementers who would adopt or reject it depending on whether it is practicable or not or suits its clientele to decrease uncertainties. In this study there is no mention of training on the new idea (implementation of the policy). However, scholars such as Virgilio \& Virgilio (2001) argue that the implementation process is interactive and needs effective communication strategies that can guide, teach, direct and empower teachers for successful implementation of the policy. This interaction could give feedback to SM on whether or not teachers were solidly grounded in the LiEP implementation. Again, their interaction could energize and inspire the team to soldier on even if there are problems. Lack of professional communication and proper guidance from SM's weakened classroom practices in most primary schools studied. Teachers expect strong leadership concerning pedagogical issues. In this regard the disconnectedness between SM and teachers led to unsuccessful LiEP implementation.

\section{Burnout and frustration amongst teachers}

Communication is supposed to build relationships that would enable policy agents to interact with facilitators for professional development. There is an indication that there was a spirit of helplessness and burn out amongst teachers and that was contributed by lack of input from their supervisors especially in Standards One and Two where languages of instruction were introduced. As Nudzor (2009) argues, the conception of the policy indicates that policies are a site of struggle, negotiation and dialogue, but this was not evident from the way teachers employed their implementation strategies, it only resulted in burnout and frustration. In the LiEP implementation, the expectation was to see teacher-led communication, collaboration and sharing of ideas and experiences that support changes expected in the LiEP and move teachers to a higher level of reflection especially in rural primary schools. Implementation strategies that sustain teacher motivation such as communication, in-house training and commitment that guide future direction of the implementation process were not revealed by the data, but instead the lack of communication amongst teachers contributed to teachers finding the implementation process daunting, confusing and disappointing. Virgilio and Virgilio (2001) caution that most implementation processes fail because supervisors neglect to provide staff with development opportunities.

Like the eagle leadership theory suggests, the findings indicated that there was a lack of opportunities for teachers to explore themselves and impact on other teachers and learners because three of the primary schools results showed poor academic performance ranging from $23-25 \%$ pass. The results devalue and undermine teachers' professionalism and training. An effective and practical tool such as effective communication was lacking to produce comprehensive and robust exchange of delivery techniques. Teachers could have adopted communication styles for maximum reception, exchange of information and understanding of 
the concept of communication richness in their endeavour to seek meaningful personal and professional lines in the implementation process.

\section{Lack of commitment by parents}

While some parents made an effort to visit the primary schools to learn about their children's progress, there was potential rupture between the primary schools and parents. Parents were forced by different circumstances not to show commitment and support to their children's education in rural primary schools. The reasons varied from one region to another such as communication barriers, illiteracy, cultural practices, demanding jobs, poverty and other social problems. Hence, whatever parents do could affect learners' progress in different ways as regards the LiEP implementation. SM and teachers reported that parents kept their children at home when it was time for cattle vaccination, hunting and gathering season or any other cultural events that they were involved in. On the basis of the above, the impression is that the fact that parents registered their children at school could mean that they wanted to transform their children's lives into better ones and have a bright future, but circumstances beyond their control hindered their intentions to show commitment and effective communication could be one of them.

Parents needed to be sensitized about the importance of children's education and how supportive they could be through effective communication between the schools and parents. The languages of instruction prescribed by the LiEP leave out some parents to contribute towards their learners' education because they do not speak the languages. It may be difficult for the parents who do not speak the school languages to assist their children with school work. Again, if the concepts in the school curriculum are not culture related the parents may not be in a position to help because they are not familiar with them. In this way the parents might also feel detached from their learners' education. The diffusion of innovation theory (Rogers, 1995) seems not to have been diffused to parents to join in problems solving issues to accomplish a common goal.

Like the eagle leadership philosophy theorizes, the SM teams should be eagles and parents should be the prey. Schools should find ways of involving parents in their children's education. However, primary schools in rural areas gave up communication with parents too quickly because of the language barrier. The giving up on communication replicates surrendering to the size and strength of the prey. The schools "gave up the fight to regain their territory" as schools to convince parents on the importance of their children's education. Schools had no weapons to address the challenges, risks and demands of the implementation process. Hence, both school management and teachers failed to protect their mandate by leaving out the most important people - the parents. Hence, some parents got angry and vented their anger on teachers when they were asked to assist their children with homework in English or Setswana. This is an indication that it is the parents "who protected and won their territory", not the teachers. These are the opposite characteristics of the eagle as it is a fearless bird that never surrenders to challenges. Instead, it displays remarkable hunting strategies that primary schools lack. Lee (2016:3) endorses parents' behavior by arguing that,

...everyday in this country we are designing and building new schools... what we are not doing is focusing on the ways in which we are communicating with our stakeholders - our employees, our parents, our neighbours, the business owners, our elected officials, the taxpayers or reporters who write stories. We are not paying enough attention to the relationships with those around us - the relationships that provide the long-term, sustained support for public education in our communities. 
Concerning the above quotation, high quality communication rests on a mutual respect built between schools and parents so that parents can recognize and serve schools in its various activities.

\section{IMPLICATIONS FOR THE POLICY AGENTS}

The LiEP may not be successfully implemented due mainly to the fluid situation in effective communication in primary schools and regions that lead to teachers' frustration. Education officers are not effectively playing their role as effective communicators and they inject the same attitude to school management teams. This trickles down to teachers and eventually to learners.

Once there is a detachment and lack of commitment due to lack of communication from policy agents, it can impact negatively on learners because they would not be benefiting from the languages of instruction. This could brew other problems that could be directly or indirectly linked to the implementation of the language-in-education policy such as: language related problems, high school dropout and playing truancy amongst learners.

The other implication is that the language-in-education policy was rolled out on a "hit and run basis" with no delivery strategies in place such as dialoguing, collaboration and networking. This goes back to the policy makers and other stakeholders to deliver the policy through effective communication on how it is supposed to be implemented and with what strategies.

\section{CONCLUSION}

Lack of communication by Education Officers and School Management teams in primary schools to support the implementation of the language-in-education policy, pedagogical practices and academic performance was found lacking and it devalued teacher professionalism and brewed resistance to expected changes. Communication as a strategy for the implementation of the LiEP is believed to build good relationship and motivate others to cooperate, hence, the LiEP implementers have to find comprehensive communication strategies for their regions and schools. With the evidence provided, it has proven that without communication the implementation of the language-in-education policy would fail. Its absence in primary schools only brewed confusion and devastation on the policy agents. It limited teachers, SM teams and learners' growth and development. To avoid unnecessary hiccups at supervisory level, effective communication through pre-service meetings, handouts and small group meetings were necessary to support the implementation process for achievement of positive results.

The conceptual framework ran parallel to the practices of Education Officers and SM teams regarding the issue of communication in primary schools. The implementers lacked vision, could not "fly high" and they failed to guide and teach young ones (teachers) by empowering them to face the challenges and risks of the implementation process through communication. EOs and SM teams could not get feedback from teachers due to lack of effective communication channels in place and this meant that even higher educational authorities would not receive this feedback. Therefore, the implication is that effective communication as a LiEP implementation strategy failed the good intention of the policy and the mission and vision of primary schools.

\section{References}

Arlestig, H. (2007). Principals' Communication Inside Schools: A Contribution to School Improvement? The Education Forum (71), $263-273$. 
Bardach, E. (1998). Getting agencies to work together: The practice and theory of managerial craftsmanship. Washington, DC: Brookings Institution Press.

Contandriopoulos, D., \&Brouselle, A. (2012). Evaluation models and evaluation use. Evaluation,18 (1), 61-77.

Covey, S.(2004). The $8^{\text {th }}$ Habit - From effective to greatness. New York: Free Press.

Gray, B., \& Wood, D. (1991). Collaborative alliances: Moving from practice to theory. Journal of Applied Behavioral Science, 27 (2), 3- 22.

Lee, C. (2016). Why School Communication Matters: A matter of Urgency, Obstacles are the entry point.

Lotitch, P. (2013). What is the impact of communication on organizational culture? The Thriving Small Business: Vision - Strategy Development Growth.

Nudzor, H.P. (2009). Re-conceptualising the paradox in policy implementation: a post-modernist conceptual approach: Discourse: Studies in the Cultural Politics of Education, 30 (4), 501-513.

Skilton, E. E. (1992). Acquisition policy planning and litigation: Language planning in the context of Y.S.V. School District of Philadelphia. WPEL, 8 (2), 55-82.

Stubbs, S., Moss, S., \& Papastefanou, N. (2012). Human Communication: Principles and Contexts. London: McGrawHill.

Patnaik, S, (2007). Communication concepts, theories and models. In Communication Models: unit 2: Listening and Communication English 9 slides - Mr Hill.

Virgilio, S. J., \& Virgilio, I. R. (2001). The role of the principal in curriculum implementation. Education, 104 (4), $346-350$.

Wang, H. (2006). An implementation study of the English as a foreign language curriculum policies in the Chinese Tertiary context. Unpublished thesis. Queens University. Canada. 